\title{
Impact of Pharmacological Manipulation of the $\kappa$-Opioid Receptor System on Self-grooming and Anhedonic-like Behaviors in Male Mice
}

\author{
Eduardo R. Butelman, Bryan D. McElroy, Thomas E. Prisinzano, and Mary Jeanne Kreek
}

Laboratory on the Biology of Addictive Diseases, the Rockefeller University, New York, New York (E.R.B., B.D.M., M.J.K.), and Department of Medicinal Chemistry, School of Pharmacy, University of Kansas, Lawrence, Kansas (T.E.P.)

Received January 8, 2019; accepted April 9, 2019

\begin{abstract}
The kappa $(\kappa)$ opioid receptor/dynorphin system modulates depression-like states and anhedonia, as well adaptations to stress and exposure to drugs of abuse. Several relatively shortacting small molecule $\kappa$-receptor antagonists have been synthesized, and their behavioral profile has been examined under some conditions. The hypothesis of this study is that pharmacological manipulations of the $\kappa$-receptor system will result in changes in ethologically relevant anhedonic-like behaviors in mice. Adult male C57BL/6j mice $(n=6-8)$ were examined for self-grooming behavior in the splash test (in which robust selfgrooming is elicited by spraying the dorsum of the mouse with a sucrose solution). The $\kappa$-agonist salvinorin A $(0.56-1.8 \mathrm{mg} / \mathrm{kg})$ produced dose-dependent decreases in self-grooming, a marker of anhedonia. The selectivity, potency, and duration of action of two relatively short-acting $\kappa$-antagonists, LY2444296 [(S)-3-fluoro-4-(4-((2-(3-fluorophenyl) pyrrolidin-1-yl)methyl) phenoxy)benzamide] and LY2795050 [3-chloro-4-(4-((2S)-2pyridin-3-ylpyrrolidin-1-yl)methyl) phenoxy)benzamide], were
\end{abstract}

studied for their effectiveness in preventing grooming deficits caused by salvinorin A $(1.8 \mathrm{mg} / \mathrm{kg})$. $\kappa$-selective doses of both LY2444296 $(0.032-1 \mathrm{mg} / \mathrm{kg})$ and LY2795050 $(0.032-0.32 \mathrm{mg} / \mathrm{kg})$ dose- and time-dependently prevented the grooming deficits caused by salvinorin A $(1.8 \mathrm{~m} / \mathrm{kg})$. We also found that a $\kappa$-selective dose of each of these antagonists decreased immobility in the forced swim test, a common test of anti-anhedonia effects. This study shows that the $\kappa$-receptor system is involved in an ethologically relevant measure of anhedonia, and that $\kappa$-selective doses of these antagonists can produce effects consistent with rapid antianhedonia.

\section{SIGNIFICANCE STATEMENT}

Activation of the $\kappa$-opioid receptor system results in grooming deficits in mice, an ethologically relevant marker of anhedonia. Shorter acting $\kappa$-antagonists are able to cause effects consistent with rapid antianhedonia.

\section{Introduction}

Kappa $(\kappa)$ opioid receptors and their endogenous neuropeptide agonists (the dynorphins) are involved in several biobehavioral mechanisms, including anhedonia, dysphoria, stress responsivity, and adaptations to repeated exposure to drugs of abuse (Beardsley et al., 2005; Carr et al., 2010; Butelman et al., 2012; Van't Veer and Carlezon, 2013; Leitl et al., 2014). The most widely used selective $\kappa$-antagonists to date-including norbinaltorphimine dihydrochloride (nor-BNI) and (3R)-7-hydroxy- $N$-[(2S)-1-[(3R,4R)-4-(3-hydroxyphenyl)3,4-dimethylpiperidin-1-yl]-3-methylbutan-2-yl]-1,2,3,4tetrahydroisoquinoline-3-carboxamide (JDTic)-have been valuable tools (Portoghese et al., 1987; Beardsley et al., 2005). However, the intriguing pharmacodynamic and pharmacokinetic

This work was supported by the National Institutes of Health National Institute on Drug Abuse [Grant R01 DA018151].

https://doi.org/10.1124/jpet.119.256354. properties of these compounds (which can include slow onset, slow emergence of selectivity, and extremely long duration of action) can complicate the design and interpretation of in vivo studies (Endoh et al., 1992; Broadbear et al., 1994; Ko et al., 2003; Melief et al., 2011). It has been suggested that these longer-acting $\kappa$-antagonists are "receptor-inactivating agents" that may function at least in part by producing complex downstream functional changes (Chavkin et al., 2019). Several groups have developed shorter-acting selective $\kappa$-antagonists, with more "canonical" pharmacodynamics and pharmacokinetics, and classic competitive properties (Grimwood et al., 2011; Peters et al., 2011; Rorick-Kehn et al., 2014).

Some of these shorter-acting $\kappa$-antagonists have reached the clinical investigation stage (Lowe et al., 2014; Reed et al., 2018). A $\kappa$-antagonist radiotracer, ${ }^{11} \mathrm{C}-\mathrm{LY} 2795050$ [3-chloro-4-(4-((2S)2-pyridin-3-ylpyrrolidin-1-yl)methyl) phenoxy)benzamide] has also been developed based on one of these chemical templates, and has been used to examine $\kappa$-receptor populations,

ABBREVIATIONS: FST, forced swim test; JDTic, (3R)-7-hydroxy- $N$-[(2S)-1-[(3R,4R)-4-(3-hydroxyphenyl)-3,4-dimethylpiperidin-1-yl]-3methylbutan-2-yl]-1,2,3,4-tetrahydroisoquinoline-3-carboxamide; LY2444296, (S)-3-fluoro-4-(4-((2-(3-fluorophenyl) pyrrolidin-1-yl)methyl)phenoxy)benzamide; LY2795050, 3-chloro-4-(4-((2S)-2-pyridin-3-ylpyrrolidin-1-yl)methyl) phenoxy)benzamide; nor-BNI, norbinaltorphimine dihydrochloride; PET, positron-emission tomography; $\kappa$-receptor, kappa-opioid receptor; $\mu$-receptor, mu-opioid receptor; U50,488, (trans)-3,4-dichloro- $N$-methyl- $N$-[2-(1pyrrolidinyl)-cyclohexyl]benzeneacetamide. 
LY2444296<smiles>NC(=O)c1ccc(Oc2ccc(CN3CCCC3c3cccc(F)c3)cc2)c(F)c1</smiles>

LY2795050

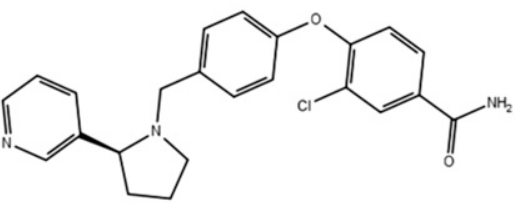

Fig. 1. Chemical structures of LY2444296 and LY2795050 (left and right panels, respectively). in positron-emission tomography (PET) neuroimaging studies in humans and animals (Naganawa et al., 2014; Pietrzak et al., 2014; Placzek et al., 2019).

In animal models, some of these shorter acting $\kappa$-antagonists have exhibited antidepressant-like and anxiolytic-like effects, as well as effectiveness in decreasing alcohol self-administration (Rorick-Kehn et al., 2014; Domi et al., 2018). We found that one such tool compound, LY2444296 [(S)-3-fluoro-4-(4-((2-(3fluorophenyl) pyrrolidin-1-yl)methyl)phenoxy)benzamide, also known as FP3FBZ] (Melief et al., 2011), prevented the depressant-like and anxiety-like effects that emerged after the end of chronic extended-access cocaine self-administration in rats (Valenza et al., 2017). However, the in vivo profile of some of these ligands is not fully understood, based on available findings in rodents (Melief et al., 2011; Huang et al., 2016a,b; Valenza et al., 2017).

To more fully understand the behavioral profile of these antagonists with respect to anhedonic-like behaviors, we have compared for the first time two structurally related compounds: LY2444296 and the nonradioactive form of LY2795050 (Pietrzak et al., 2014; Placzek et al., 2019). This included an evaluation of doses of these antagonists that exhibit $\kappa$-over $\mu$-receptor selectivity in a behavioral end point (Rorick-Kehn et al., 2014, 2015) because these compounds have only relative binding selectivity (Kim et al., 2013).

Furthermore, this study also examined for the first time the pharmacology of $\kappa$-receptor ligands in the mouse splash test, a simple and repeatable assay that measures self-grooming (Yalcin et al., 2008; Williams et al., 2018). Self-grooming in rodents is a highly regulated homeostatic behavior, mediated by specific brain regions, including the striatum and other sites known to express dynorphin and $\kappa$-receptors (Berridge and Whishaw, 1992; Unterwald et al., 1994; Kalueff et al., 2016). Studies have demonstrated that a decrease in grooming in the splash test can be an ethologically relevant display of anhedonia (Yalcin et al., 2008; Sens et al., 2017).

\section{Materials and Methods}

Mice. Adult male C57/bl6j mice were purchased from Charles River or Jackson Laboratories; they were 9 to 10 weeks of age upon arrival to the Association for Assessment and Accreditation of Laboratory Animal Care (AAALAC)-approved facility. The mice were habituated to the facility at least 7 days before use. The mice were housed in groups of three to four, with standard sawdust bedding, in a room controlled for temperature $\left(\approx 20-22^{\circ} \mathrm{C}\right)$ and humidity, with a 12-hour light/dark cycle (lights on at 07:00). The experimental procedures were performed in the same room as their housing. The procedures typically took place between 09:00 and 13:00 hours. A total of 136 male mice were used in these studies.

All animal studies were approved by the Rockefeller University Animal Care and Use Committee, in accordance with the National Research Council's Guide for the Care and Use of Laboratory Animals.

\section{Procedures}

Splash Test. The splash test is a simple and repeatable test of selfgrooming in mice (Yalcin et al., 2008). Prior studies have shown that anhedonia and depressant-like effects are associated with decreased grooming time in this assay (Yalcin et al., 2008; Khemissi et al., 2014). Mice were habituated to the procedure in one session before being used in experiments. A single mouse was placed in an individual transparent cage $(26.7 \mathrm{~cm}$ length $\times 15.2 \mathrm{~cm}$ width $\times 12.1 \mathrm{~cm}$ height) with regular bedding for 1 minute, to allow initial habituation to the environment. This was followed by spraying approximately $0.7 \mathrm{ml}$ of $10 \%(\mathrm{w} / \mathrm{v})$ sucrose solution in water on the dorsum of the mouse, using a spray bottle from a distance $\approx 10 \mathrm{~cm}$. A 5 -minute observation period was started immediately, in which the cumulative time of selfgrooming was measured manually with a stopwatch by an experienced observer under blinded conditions (i.e., the observer was unaware of the pharmacological conditions under study, such as $\kappa$-agonist or antagonist dose). Consecutive experiments in the same mice were separated by at least 96 hours. In within-subjects studies, consecutive experiments in the same mice were balanced for order.

Thermal Antinociception. Oxycodone-induced thermal antinociception was studied with the hot plate assay (model 39D Hot Plate Analgesia Meter; IITC Life Science, Woodland Hills, CA) at a temperature of $54^{\circ} \mathrm{C}$. Mice were placed inside a cylindrical transparent Plexiglas enclosure $(30.6 \mathrm{~cm}$ height $\times 19.4 \mathrm{~cm}$ diameter) which was placed on top of the hot plate. Mice underwent an individual habituation session, in which they were placed in the enclosure on the hot plate apparatus at room temperature for two 1 -minute periods, separated by $\approx 10$ minutes. Starting at least 1 day after habituation, the hot plate experiments $\left(54^{\circ} \mathrm{C}\right)$ were

\section{Salvinorin A (SVN A): Graded doses in the splash test $(n=7)$}

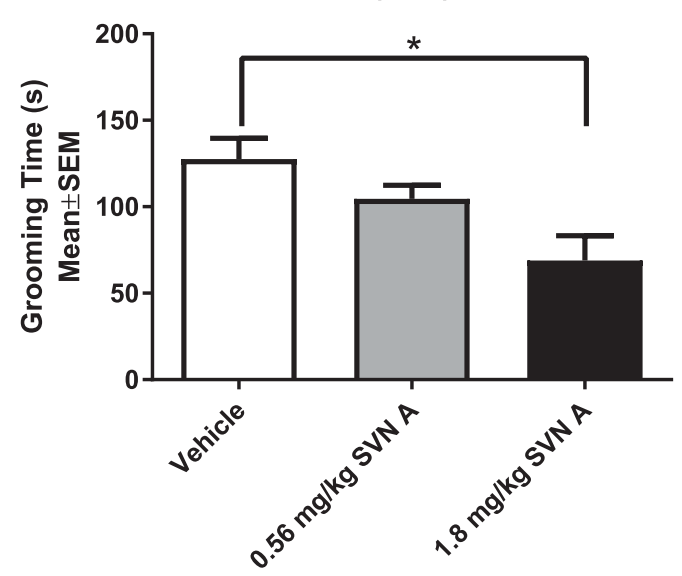

Fig. 2. Effects of salvinorin $A$ in the splash test. Vehicle or salvinorin A $(0.56$ or $1.8 \mathrm{mg} / \mathrm{kg})$ were injected i.p. 15 minutes before the splash test. Total grooming time was quantified over 5 minutes. A one-way repeated measures ANOVA was significant $(\mathrm{F}[2,12=7.52 ; P=0.0080)$. Dunnett's test shows that salvinorin A $(1.8 \mathrm{mg} / \mathrm{kg})$ decreases grooming time compared with vehicle $(P<0.05)$. 
conducted, separated at least 96 hours from each other. The sessions commenced with two baseline withdrawal latency determinations, separated by approximately 10 minutes. A withdrawal response was recorded as a jump or hind paw lick, with a maximum latency of 45 seconds timed by stopwatch. If an animal exhibited baseline latencies $>20$ seconds, it was removed from study for that session.

After the baseline determination, the mouse was injected with vehicle or oxycodone (i.p.) and was tested in a time course procedure, with latencies determined at predetermined times (e.g., 15-120 or 180 minutes). If at any of these times, the mouse reached the cutoff latency (i.e., 45 seconds) without a withdrawal response, it was removed from the hot plate, and the cutoff value was assigned for data analysis. The cylinder and hot plate were wiped with water between mice, as needed.

Forced Swim Test. The Porsolt mouse forced swim test (FST) was used as a 1-day procedure (Porsolt et al., 1978; Castagné et al., 2009) under blinded conditions. Individual mice were placed in a transparent Plexiglas cylinder $(24.5 \mathrm{~cm}$ height $\times 11.0 \mathrm{~cm}$ diameter $)$ with water at $21 \pm 2{ }^{\circ} \mathrm{C}$ for 6 minutes. Immobility was defined as the cessation of all movements except for those necessary to stay afloat, for at least 2 seconds. Total immobility time was timed cumulatively for the last 4 minutes of the session. The water was changed between mice. Separate groups of mice were used once in this test, and they were preinjected with vehicle, LY244496, or LY2795050 (0.5-hour pretreatment).

\section{A}

\section{A Oxycodone dose-effect curve:} Antinociception ( $n=8 /$ group)

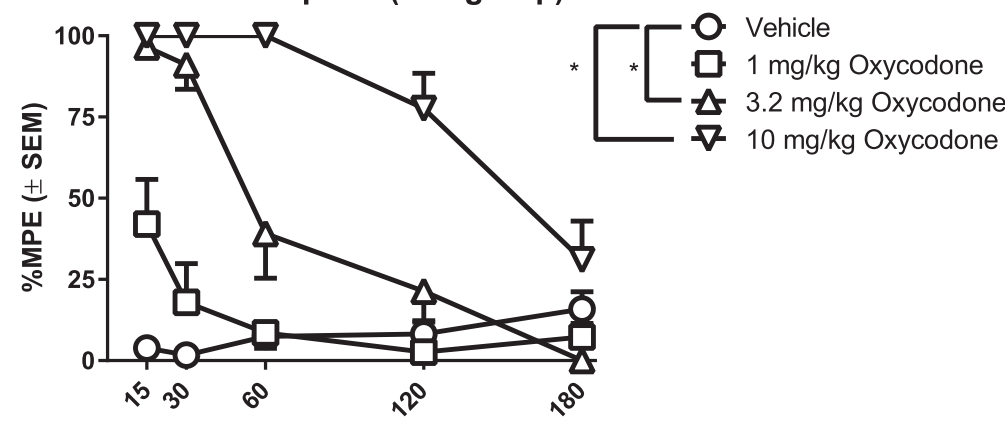

Time after oxycodone injection $(\mathrm{min})$

B

LY2444296 pretreatment to oxycodone (3.2 mg/kg; $\mathrm{n}=8$ )

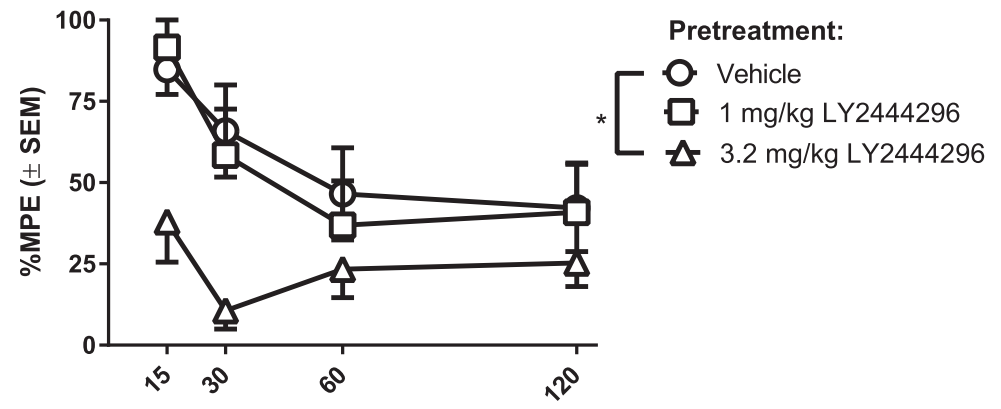

Time after oxycodone injection (min)

C

LY2795050 pretreatment to oxycodone (3.2 mg/kg; $\mathrm{n}=6$ )

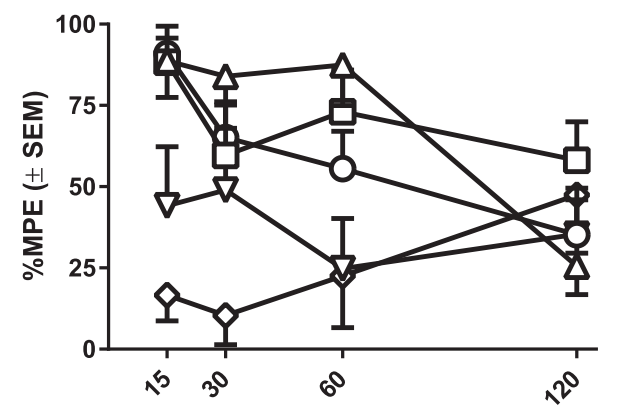

Pretreatment:

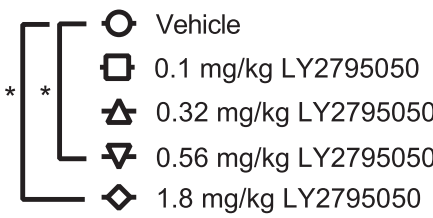

Fig. 3. Oxycodone-induced antinociception in the hot plate assay (please note different abscissae). (A) Dose-effect curve for oxycodone alone (vehicle, $1,3.2$, and $10 \mathrm{mg} / \mathrm{kg}$ ), analyzed with a two-way mixed ANOVA (oxycodone dose $\times$ time; repeated measures on the last factor). There were significant main effects of oxycodone dose $(\mathrm{F}[3,28]$ $=95.15 ; P<0.0001)$, time $(\mathrm{F}[4,112]=29.48 ; P<0.0001)$, and their interaction $(\mathrm{F}[12,112]=10.69 ; P<0.0001)$. Dunnett's test shows that oxycodone at 3.2 and $10 \mathrm{mg} / \mathrm{kg}$ was significantly different from vehicle. (B and C) Effects of 0.5 -hour pretreatment (PT) with doses of (B) LY2444296 or (C) LY2795050 to oxycodone $(3.2 \mathrm{mg} / \mathrm{kg})$, respectively. Data were analyzed with two-way repeated measures ANOVAs (antagonist dose $\times$ time). For LY2444296, there was a main effect of antagonist dose $(\mathrm{F}[2,14]=9.85 ; P=0.0021)$. Dunnett's test shows that the largest dose of LY2444296 $(3.2 \mathrm{mg} / \mathrm{kg})$ was different from vehicle pretreatment. For LY2795050, there was also a main effect of antagonist dose $(\mathrm{F}[4,20]=11.23 ; P<0.0001)$. Dunnett's test shows that the two largest doses of LY2795050 (0.56 and $1.8 \mathrm{mg} / \mathrm{kg})$ were different from vehicle pretreatment.

Time after oxycodone injection (min) 


\section{Design}

Unless otherwise stated, all studies were performed with $n=8$ per group.

Splash Test (Self-Grooming). A dose-effect curve was determined with the $\kappa$-selective agonist salvinorin A (vehicle, 0.56 and $1.8 \mathrm{mg} / \mathrm{kg} ; 15$ minutes before the splash test; within-subjects). Because the largest dose of salvinorin $\mathrm{A}(1.8 \mathrm{mg} / \mathrm{kg})$ produced rapid and robust decreases in self-grooming, we then examined the dose- and timedependence of antagonist pretreatment to this dose. In separate experiments, LY2444296 (vehicle, 0.032, 0.1, 0.32, $1 \mathrm{mg} / \mathrm{kg}$; withinsubjects) was administered 0.5 hours before salvinorin $\mathrm{A}(1.8 \mathrm{mg} / \mathrm{kg})$. We then studied LY2795050 (vehicle, 0.032, 0.1, $0.32 \mathrm{mg} / \mathrm{kg}$; withinsubjects) administered 0.5 hours before salvinorin A $(1.8 \mathrm{mg} / \mathrm{kg})$. In a comparison study in separate groups of mice, we determined whether nor-BNI (10 mg/kg or vehicle; between-subjects; 24 -hour pretreatment) was able to prevent grooming deficits caused by salvinorin A $(1.8 \mathrm{mg} / \mathrm{kg})$. This dose and pretreatment time of nor-BNI has been shown to produce $\kappa$-antagonist effects in mice in other assays (Broadbear et al., 1994). We then compared the duration of action of effective doses of LY2444296 (1 mg/kg) or LY2795050 $(0.1 \mathrm{mg} / \mathrm{kg})$ as pretreatment to salvinorin A $(1.8 \mathrm{mg} / \mathrm{kg})$. This was performed by varying the antagonist pretreatment time (i.e., $0.5,3$, and 24 hours) before the salvinorin $\mathrm{A}(1.8 \mathrm{mg} / \mathrm{kg})$ injection, within-subjects.

Antagonist Effects of LY2795050 Given as Pretreatment or Posttreatment to the $\kappa$-Agonist U50,488 in the Splash Test. Rapid onset of $\kappa$-antagonist effects is one of the potential distinguishing features of novel compounds such as LY2795050 (Zheng et al., 2013). We therefore examined whether LY2795050 could be effective against the grooming deficits caused by the selective $\kappa$-agonist U50,488 [(trans)-3,4dichloro- $N$-methyl- $N$-[2-(1-pyrrolidinyl)-cyclohexyl]benzeneacetamide] even if the antagonist was administered as a posttreatment. Salvinorin $\mathrm{A}$ is known to be a short-acting compound in vivo (Fantegrossi et al., 2005; Hooker et al., 2008). We therefore selected the standard $\kappa$-agonist U50,488 for this study because its duration of action may be more appropriate (Broadbear et al., 1994; McLaughlin et al., 2006; Paris et al., 2011). We administered LY2795050 (0.1 mg/kg or vehicle) as a 0.5 -hour pretreatment or as a 0.25 -hour posttreatment to U50,488 (3.2 $\mathrm{mg} / \mathrm{kg})$. The splash test occurred 0.5 hours after U50,488 administration in all cases. The dosing and timing conditions for U50,488 were based on published studies in mice (Broadbear et al., 1994; McLaughlin et al., 2006). This dose of U50,488 also causes grooming deficits in this assay (unpublished observations).

Blockade of Oxycodone-Induced Antinociception in the Hot Plate Assay. Compounds such as LY2795050 and congeners have relative $\kappa>\mu$ receptor binding selectivity and could therefore also produce $\mu$-antagonist effects at large enough doses (Kim et al., 2013; Rorick-Kehn et al., 2014, 2015). These experiments were designed to determine what doses of LY2444296 and LY2795050 could block the antinociceptive effects of the $\mu$-agonist oxycodone (Beardsley et al., 2004; Peckham and Traynor, 2006). We first determined the oxycodone dose-effect curve (vehicle, $1,3.2,10 \mathrm{mg} / \mathrm{kg}$ ). We found that a $3.2 \mathrm{mg} / \mathrm{kg}$ dose of oxycodone was the smallest dose to produce nearmaximal antinociceptive effects in this assay. In separate experiments, we then determined whether LY2444296 (vehicle, 1 and $3.2 \mathrm{mg} / \mathrm{kg}$ ) or LY2795050 (vehicle, $0.1,0.32,0.56,1.8 \mathrm{mg} / \mathrm{kg}$ ) could prevent the antinociceptive effects of oxycodone $(3.2 \mathrm{mg} / \mathrm{kg})$ when each of the antagonists was administered as a 0.5 -hour pretreatment.

Forced Swim Test. In separate experiments, we determined whether a single pretreatment injection of LY2444296 $(1 \mathrm{mg} / \mathrm{kg}$ or vehicle) or LY2795050 (0.1 $\mathrm{mg} / \mathrm{kg}$ or vehicle) could decrease the cumulative immobility time in the FST. Each compound was injected 0.5 hours before the FST. Each mouse was used only once in this assay.

Statistical Analyses. Splash test data were analyzed with $t$ tests or repeated measures ANOVA. The hot plate data were analyzed after conversion to percentage of maximum possible effect (\%MPE), by the following standard equation: [(Cutoff latency - Test latency)/(Cutoff latency - Baseline latency) $] \times 100 \%$. The FST immobility data (in seconds) $(n=7)$

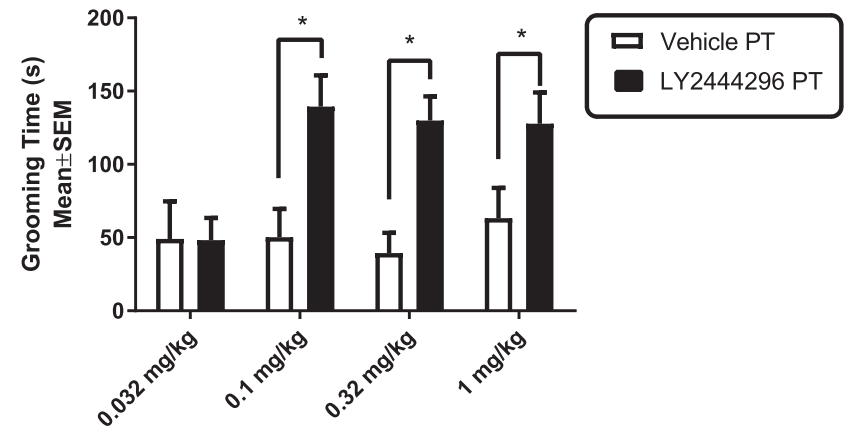

LY2444296 pretreatment dose,

0.5 hours before salvinorin A $(1.8 \mathrm{mg} / \mathrm{kg})$

B

\section{LY2795050: Splash Test}

$(n=7)$

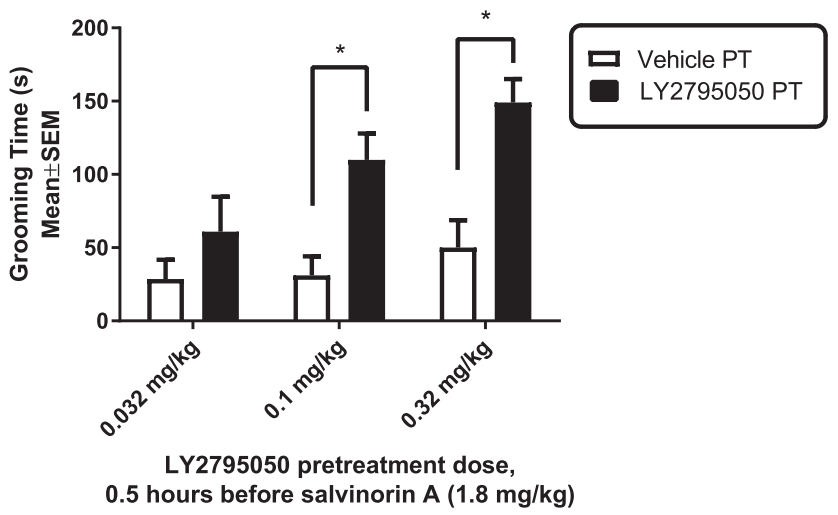

C

nor-BNI: Splash Test

( $n=8$ /group)

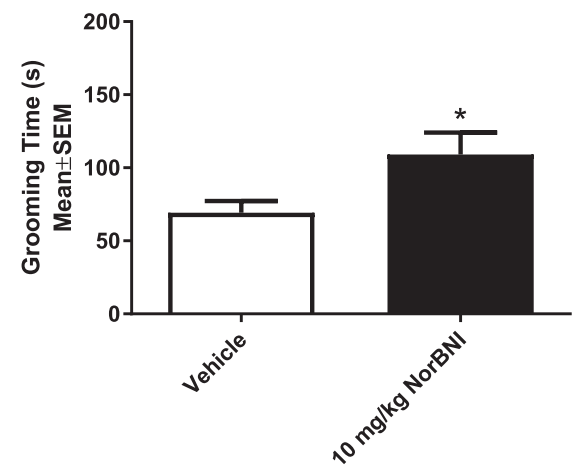

nor-BNI pretreatment,

$24 \mathrm{~h}$ before salvinorin $A(1.8 \mathrm{mg} / \mathrm{kg})$

Fig. 4. Effects of antagonists in preventing grooming deficits induced by salvinorin A $(1.8 \mathrm{mg} / \mathrm{kg})$. Effects of graded doses of (A) LY2444296 and (B) LY2795050 (0.5-hour pretreatment; PT) in preventing grooming deficits induced by salvinorin A, respectively. Each antagonist dose (black bars) was compared with its vehicle (open bars) condition, in two-way repeated measures ANOVA (antagonist dose $\times$ pretreatment condition). For LY2444296, there was a main effect of the antagonist dose $(F[1,27]=26.2$; $P<0.0001)$ and an interaction between the antagonist dose and PT condition $(\mathrm{F}[3,27]=3.09 ; P=0.044)$. Sidak's test shows that the three largest doses of LY2444296 $(0.1,0.32$, and $1 \mathrm{mg} / \mathrm{kg})$ were different from their respective vehicle pretreatments. For LY2795050, there was a main effect of the antagonist dose $(\mathrm{F}[1,19]=32.54 ; P<0.0001)$ and an interaction $(\mathrm{F}[2,19]$ $=3.80 ; P=0.041$ ). Sidak's test shows that the two largest doses of LY2795050 $(0.1$ and $0.32 \mathrm{mg} / \mathrm{kg}$ ) were different from their respective vehicle pretreatment. (C) Nor-BNI $(10 \mathrm{mg} / \mathrm{kg})$ or vehicle were studied as a 24-hour PT before salvinorin $\mathrm{A}$ in two separate groups. An unpaired $t$ test $\mathrm{t}[14]=2.32 ; P<0.04)$ shows that nor-BNI decreased immobility time compared with vehicle. 
were analyzed with unpaired $t$ tests, with each $\kappa$-antagonist compared with its own vehicle group. Appropriate post hoc tests were used for follow up. The statistical software used was GraphPad Prism 6.0 (GraphPad Software, San Diego, CA); the alpha level of significance was $P \leq 0.05$. If there were missing data for a subject in withinsubjects comparisons, data were removed from the analysis.

Drugs and Injections. Salvinorin A was extracted from Salvia divinorum leaves as described elsewhere (Munro and Rizzacasa, 2003; Tidgewell et al., 2004) and was dissolved daily (1:1:8 by volume, ethanol/Tween 80/sterile water). The structure of salvinorin A has been described elsewhere (Roth et al., 2002). LY2444296 ((S)-3-fluoro4-(4-((2-(3-fluorophenyl)pyrrolidin-1-yl)methyl)phenoxy)benzamide) (Fig. 1) was kindly supplied by Eli Lilly Co. We used the hydrochloride salt of LY2444296 herein, and doses are expressed as the base. LY2795050 (3-chloro-4-(4-(((2S)-2-pyridin-3-ylpyrrolidin-1-yl)methyl) phenoxy)benzamide) (Fig. 1) (Zheng et al., 2013) was purchased from BOC Sciences (Shirley, NY). LY2444296 and LY2795050 were dissolved 1:1:8 in ethanol/Tween $80 /$ sterile water by volume. Oxycodone $\mathrm{HCl}$ and nor-BNI (Sigma-Aldrich, St. Louis, MO) were dissolved in sterile water. U50,488 was kindly provided by the National Institute on Drug Abuse Drug Supply Program and was dissolved in sterile water. Dose ranges and pretreatment times for each compound were selected from published studies in mice and pilot studies. All drugs were injected intraperitoneally, and the injection volumes were typically $10 \mathrm{ml} / \mathrm{kg}$ body weight.

\section{Results}

Salvinorin A Causes Dose-Dependent Grooming Deficits in the Splash Test. Salvinorin A caused a dosedependent reduction in grooming time in the splash test, examined within-subjects. Dunn's post hoc test showed that the salvinorin A dose of $1.8 \mathrm{mg} / \mathrm{kg}$ caused a significant decrease in total grooming time compared with vehicle (Fig. 2).

Determination of Doses of LY2444296 and LY2795050 That Cause Blockade of the Antinociceptive Effects of the $\boldsymbol{\mu}$-Agonist Oxycodone. Oxycodone caused a dose- and time-dependent antinociceptive effect in the hot plate assay (Fig. 3). The smallest dose of oxycodone to cause a nearmaximal effect was $3.2 \mathrm{mg} / \mathrm{kg}$. LY2444296 and LY2795050 (or vehicle) were administered as a 0.5 -hour pretreatment to oxycodone $(3.2 \mathrm{mg} / \mathrm{kg})$. Both LY2444296 and LY2795050 caused a dose-dependent blockade of the antinociceptive effects of oxycodone (Fig. 3). Thus, a dose of LY2444296 of $3.2 \mathrm{mg} / \mathrm{kg}$ and doses of LY2795050 $\geq 0.56 \mathrm{mg} / \mathrm{kg}$ each caused a significant blockade of oxycodone's effects. This finding guided the selection of appropriate doses of LY2444296 and LY2795050 to be studied for $\kappa$-selective antagonism (i.e., with doses $<3.2 \mathrm{mg} / \mathrm{kg}$ for LY2444296 and $<0.56 \mathrm{mg} / \mathrm{kg}$ for LY2795050) in the experiments that followed.

Determination of the Effectiveness of Graded Doses of LY2444296 and LY2795050 in Preventing Grooming Deficits Caused by the $\kappa$-Agonist Salvinorin A. Different doses of LY2444296 and LY2795050 were examined as a 0.5 -hour pretreatment to salvinorin A $(1.8 \mathrm{mg} / \mathrm{kg})$. Each dose of each antagonist was compared, within-subjects, to its own vehicle condition. Both LY2444296 and LY2795050 caused a dose-dependent prevention of salvinorin A-induced grooming deficits (Fig. 4). The largest doses of LY2444296 and LY2795050 alone did not have effects on grooming time compared with their own vehicle condition (data not shown). In a comparison study in separate groups of mice, nor-BNI $(10 \mathrm{mg} / \mathrm{kg}$ or vehicle; 24-hour pretreatment) also prevented salvinorin A-induced grooming deficits when studied between subjects (Fig. 4).

Duration of Action of LY2444296 and LY2795050 in Preventing Grooming Deficits Caused by Salvinorin A. The duration of action of LY2444296 (1 mg/kg) and LY2795050 $(0.1 \mathrm{mg} / \mathrm{kg})$ in preventing salvinorin A-induced grooming deficits was examined with $0.5-, 3-$ and 24 -hour pretreatments. Each condition was compared with its own vehicle determination within subjects. Both compounds caused a timedependent blockade of salvinorin A-induced grooming deficits (Fig. 5). LY2444296 was effective at 0.5 and 3 hours but not 24 hours pretreatment. LY2795050 exhibited a shorter duration of action, and was effective only at 0.5 -hour but not at 3- or 24-hour pretreatments.

Antagonist Effects of LY2795050 Administered as Pretreatment or Posttreatment to the $\kappa$-Agonist U50,488. After determination of the effects of LY2795050 $(0.1 \mathrm{mg} / \mathrm{kg})$ as a pretreatment to salvinorin A (Figs. 4 and 5), we further examined whether this antagonist would be able to block grooming deficits caused by the standard $\kappa$-agonist U50,488 when administered either as a pretreatment or as a posttreatment. LY2795050 $(0.1 \mathrm{mg} / \mathrm{kg})$ was thus administered
A

LY2444296:

Duration of antagonist action $(n=8)$

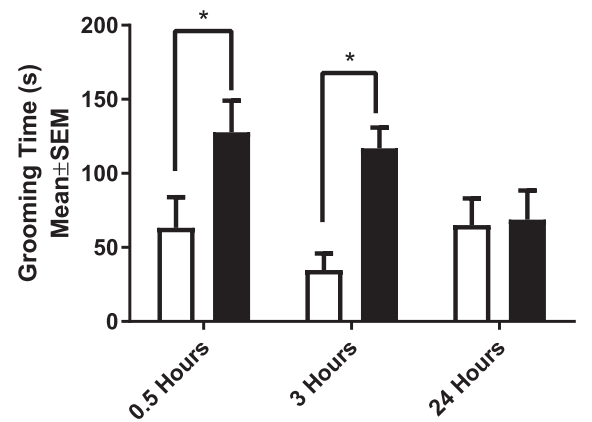

LY2444296 (1 mg/kg) pretreatment time before salvinorin A $(1.8 \mathrm{mg} / \mathrm{kg})$
B LY2795050:

Duration of antagonist action $(n=7)$

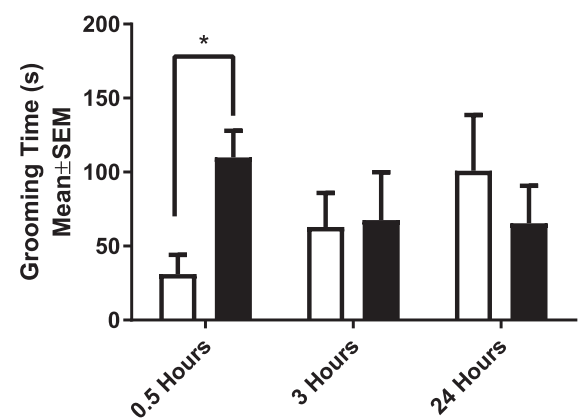

LY2795050 (0.1 mg/kg) pretreatment time before salvinorin A $(1.8 \mathrm{mg} / \mathrm{kg})$
Fig. 5. Duration of action of (A) LY2444296 $(1 \mathrm{mg} / \mathrm{kg})$ and (B) LY2795050 $(0.1 \mathrm{mg} / \mathrm{kg})$ in preventing grooming deficits induced by salvinorin A $(1.8 \mathrm{mg} / \mathrm{kg})$. Each antagonist dose (black bars) was compared with its vehicle condition, within-subjects (open bars). A mixed ANOVA was performed for each antagonist (pretreatment time $\times$ pretreatment condition, with repeated measures on the last factor). For LY2444296, there was a main effect of pretreatment time $(\mathrm{F}[1,21]=13.57 ; P=0.0014)$. Sidak's test shows that the 0.5 - and 3-hour pretreatments were significantly different from their vehicle condition. For LY2795050 there was a significant interaction between the pretreatment time and pretreatment condition $(\mathrm{F}[2,19]=6.50 ; P=0.0071)$. Sidak's test shows that only the 0.5 -hour LY2795050 pretreatment was significantly different from its vehicle condition. 
Pretreatment or post-treatment with LY2795050 relative to U50,488: Splash test $(n=8-11)$

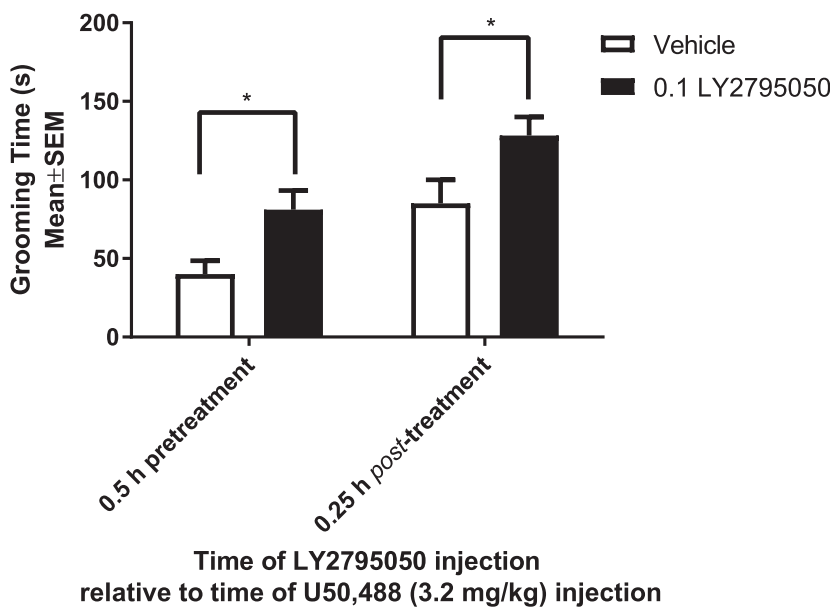

Fig. 6. Effectiveness of LY2795050 $(0.1 \mathrm{mg} / \mathrm{kg}$, or vehicle $)$ when administered as 0.5-hour pretreatment or 0.25 -hour posttreatment against grooming deficits caused by the $\kappa$-agonist U50,488 $(3.2 \mathrm{mg} / \mathrm{kg})$. The splash test was performed 0.5 hours after U50,488 injection in all cases. A mixed ANOVA was performed (LY2795050/vehicle $\times$ pretreatment/ posttreatment, with repeated measures on the first factor). We found main effects of LY2795959/vehicle $(\mathrm{F}[1,17]=26.74 ; P<0.0001)$ and pretreatment $/$ posttreatment $(\mathrm{F}[1,17]=9.69 ; P=0.0063)$. Sidak's test shows that the LY2795050 condition was significantly different from the respective vehicle condition, both when given as a 0.5 -hour pretreatment, and as a 0.25 -hour posttreatment.

as a 0.5 -hour pretreatment to U50,488 $(3.2 \mathrm{mg} / \mathrm{kg})$, or as a 0.25-hour posttreatment (i.e., with LY2795050 administered after U50,488). The splash test commenced 0.5 hours after U50,488 in all cases. The selection of U50,488 dose and timing conditions was based on prior studies (Broadbear et al., 1994; Paris et al., 2011) and unpublished observations. LY2795050 was able decrease U50,488-induced grooming deficits both when given as a pretreatment and also when given as a posttreatment (Fig. 6).

Examination of $\kappa$-Selective Doses of LY2444296 and LY2795050 in the Forced Swim Test. Based on the above findings (Figs. 4 and 5), a $\kappa$-selective dose of LY2444296 $(1 \mathrm{mg} / \mathrm{kg})$ and of LY2795050 $(0.1 \mathrm{mg} / \mathrm{kg})$ were each studied in the 1-day FST (0.5-hour pretreatment). Each of these treatments caused a decrease in immobility in this test compared with its own vehicle condition, studied between-subjects (Fig. 7).

\section{Discussion}

We found for the first time that salvinorin A, a highly selective plant-derived $\kappa$-agonist (Roth et al., 2002), produced dose-dependent grooming deficits in the splash test in mice. The doses of salvinorin A that were effective in causing grooming deficits are similar to those that caused other $\kappa$-receptor mediated effects in mice, including place aversion and decreases in striatal dopamine dialysates (Fantegrossi et al., 2005; Zhang et al., 2005).

Self-grooming in rodents is a highly regulated ethologically relevant behavior, mediated by specific brain areas (Berridge and Whishaw, 1992; Kalueff et al., 2016). Several of these areas, including the striatum, are known to have prominent $\kappa$-receptor populations (Unterwald et al., 1994). A decrease in self-grooming in rodents can be a marker of anhedonia, and it occurs after diverse behavioral and biologic stressors (Yalcin et al., 2008; Sens et al., 2017; Williams et al., 2018). Exogenous $\kappa$-agonists are also known to produce other effects indicative of anhedonia or aversion in vivo (Zhang et al., 2004; Carlezon et al., 2006). Up-regulation of endogenous Pdyn systems is also associated with anhedonia and other stress-related effects (Shirayama et al., 2004; Reed et al., 2012).

We found for the first time that relatively large doses of both LY2444296 (3.2 mg/kg) and LY2795050 (1 mg/kg) were able to antagonize the antinociceptive effects of oxycodone. The antinociceptive effects of oxycodone are mediated by $\mu$-receptors (Beardsley et al., 2004; Peckham and Traynor, 2006), so these relatively larger doses of LY2444296 and LY2795050 cannot be considered $\kappa$-selective under these conditions. This in vivo profile is consistent with the in vitro binding properties of several analogs from this chemical template, which have moderate selectivity of for $\kappa$-versus $\mu$-receptors (Kim et al., 2013; Rorick-Kehn et al., 2014). Based on this determination, we therefore focused the remaining experiments on relatively smaller doses of LY2444296 and LY2795050 so that potential $\mu$-antagonism would be less likely to affect our findings or their interpretation (see below).
A LY2444296: Forced swim test ( $n=8$ per group)
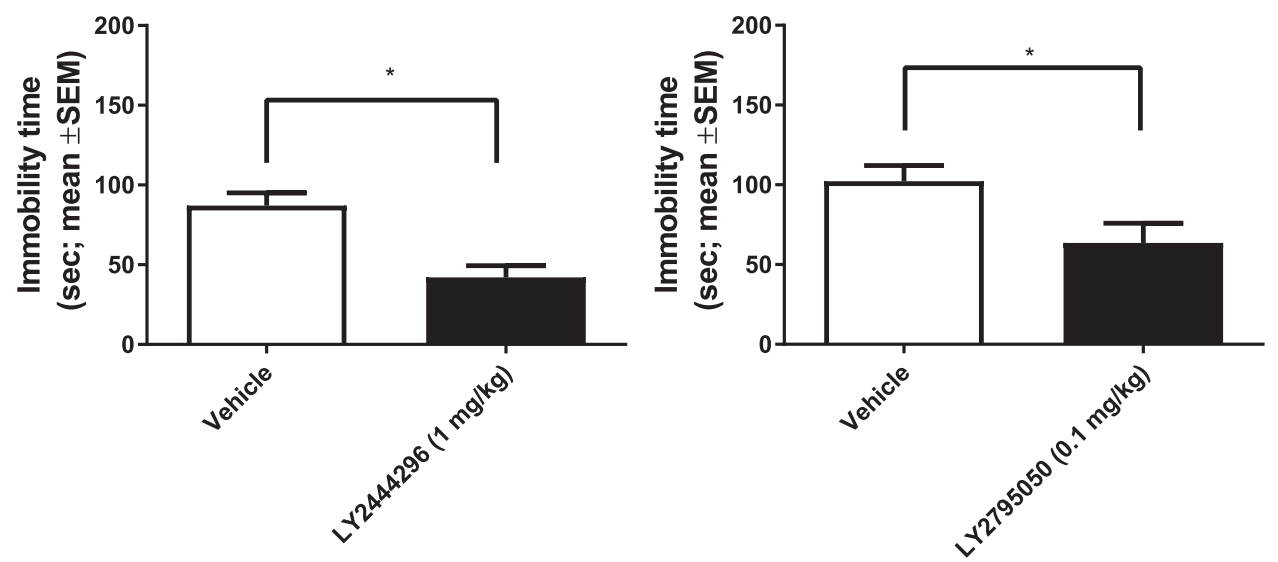

Fig. 7. Effects of (A) LY2444296 (1 mg/kg; 0.5-hour pretreatment) or (B) LY2795050 $(0.1 \mathrm{mg} / \mathrm{kg}$; 0.5-hour pretreatment) on immobility in the 1-day forced swim test procedure. Each antagonist was compared with its vehicle condition with unpaired $t$ tests. LY2444296 decreased immobility time compared with vehicle $(\mathrm{t}[14]=4.13 ; P=0.001)$, and a similar finding was made for LY2795050 (t[14] $=2.43 ; P=0.029$ ). 
Under these conditions, we determined for the first time that LY2444296 and LY2795050 dose- and time-dependently prevented salvinorin A-induced grooming deficits. LY2444296 appeared to be longer acting than LY2795050 (the former was active at 0.5 and 3 hours after administration; the latter was active at 0.5 but not 3 hours). However, it cannot be excluded that a smaller dose of LY2444296 (e.g., $0.1-0.32 \mathrm{mg} / \mathrm{kg}$ ) would have exhibited a shorter duration of action. Overall, the short duration of action of LY2795050 found herein is consistent with its selection as a PET ligand radiotracer, among compounds of this chemical template (Rorick-Kehn et al., 2014; Naganawa et al., 2016; Reed et al., 2018; Placzek et al., 2019).

In a follow-up experiment, we also determined that LY2795050 was able to decrease grooming deficits induced by the standard $\kappa$-agonist U50,488 even when administered as a posttreatment. Thus, U50,488 was administered first, followed 0.25 hours later by LY2795050, and this was followed by the splash test 0.25 hours thereafter. The rapid onset of LY2795050 in this behavioral assay corresponds well with the onset of striatal occupancy of ${ }^{11} \mathrm{C}-\mathrm{LY} 2795050$ when injected systemically as a radiotracer in rodents (Zheng et al., 2013).

Finally, we found that both LY2444296 and LY2795050, at doses that did not have $\mu$-antagonist effects, decreased immobility in the FST when administered as acute 0.5-hour pretreatments. In pilot studies, we found that the doses of these antagonists that are effective in the FST did not produce locomotor changes (data not shown). Therefore, the effects of these rapid-acting $\kappa$-antagonists on immobility in the FST are not due to a simple confound with locomotor function. The rapid effects of compounds from this chemical template in the FST (and of LY2444296) have been observed before (RorickKehn et al., 2014; Huang et al., 2016a). This is the first such examination for LY2795050, to our knowledge. Overall, this study shows that the same doses of LY2444296 and LY2795050 that can prevent $\kappa$-agonist-induced grooming deficits are also active in the FST, a common test of anhedoniaor despair-like behavior.

These are the first behavioral data on the effects of LY2795050 in any species, to our knowledge. ${ }^{11} \mathrm{C}-\mathrm{LY} 2795050$ has been used as a PET neuroimaging radiotracer in humans and animals (Pietrzak et al., 2014; Naganawa et al., 2015). The systemic doses of LY2795050 that produced behavioral effects in this study correspond relatively well with the doses that bind $\kappa$-receptors in rodents in vivo (Placzek et al., 2019). Overall, these are the first studies to examine the effects of $\kappa$-agonism and $\kappa$-antagonism on self-grooming behaviors in the splash test, and they further implicate this neurobiological system in ethologically relevant measures of anhedonia.

\section{Acknowledgments}

We are very grateful to Dr. Linda Rorick-Kehn and the Lilly Co. for their kind donation of the LY2444296 hydrochloride. We are also grateful to Dr. Linda Rorick-Kehn for helpful advice. We are grateful to Amelia Dunn for help with the preparation for these studies, and to Dr. Brian Reed. We are grateful to the Dr. Miriam and Sheldon G. Adelson Medical Research Foundation.

\section{Authorship Contributions}

Participated in research design: Butelman, McElroy, Kreek. Conducted experiments: McElroy.

Contributed new reagents or analytic tools: Prisinzano.

Performed data analysis: Butelman, McElroy.
Wrote or contributed to the writing of the manuscript: Butelman, McElroy, Prisinzano, Kreek.

\section{References}

Beardsley PM, Aceto MD, Cook CD, Bowman ER, Newman JL, and Harris LS (2004) Discriminative stimulus, reinforcing, physical dependence, and antinociceptive effects of oxycodone in mice, rats, and rhesus monkeys. Exp Clin Psychopharmacol 12:163-172.

Beardsley PM, Howard JL, Shelton KL, and Carroll FI (2005) Differential effects of the novel kappa opioid receptor antagonist, JDTic, on reinstatement of cocaineseeking induced by footshock stressors vs cocaine primes and its antidepressantlike effects in rats. Psychopharmacology (Berl) 183:118-126.

Berridge KC and Whishaw IQ (1992) Cortex, striatum and cerebellum: control of serial order in a grooming sequence. Exp Brain Res 90:275-290.

Broadbear JH, Negus SS, Butelman ER, de Costa BR, and Woods JH (1994) Differential effects of systemically administered nor-binaltorphimine (nor-BNI) on kappa-opioid agonists in the mouse writhing assay. Psychopharmacology (Berl) 115:311-319.

Butelman ER, Yuferov V, and Kreek MJ (2012) $\kappa$-Opioid receptor/dynorphin system: genetic and pharmacotherapeutic implications for addiction. Trends Neurosci 35: $587-596$

Carlezon WA Jr, Béguin C, DiNieri JA, Baumann MH, Richards MR, Todtenkopf MS, Rothman RB, Ma Z, Lee DY, and Cohen BM (2006) Depressive-like effects of the kappa-opioid receptor agonist salvinorin $\mathrm{A}$ on behavior and neurochemistry in rats. J Pharmacol Exp Ther 316:440-447.

Carr GV, Bangasser DA, Bethea T, Young M, Valentino RJ, and Lucki I (2010) Antidepressant-like effects of kappa-opioid receptor antagonists in Wistar Kyoto rats. Neuropsychopharmacology 35:752-763.

Castagné V, Porsolt RD, and Moser P (2009) Use of latency to immobility improves detection of antidepressant-like activity in the behavioral despair test in the mouse. Eur J Pharmacol 616:128-133.

Chavkin C, Cohen JH, and Land BB (2019) Repeated administration of norbinaltorphimine produces cumulative kappa opioid receptor inactivation. Front Pharmacol 10:88.

Domi E, Barbier E, Augier E, Augier G, Gehlert D, Barchiesi R, Thorsell A, Holm L, and Heilig M (2018) Preclinical evaluation of the kappa-opioid receptor antagonist CERC-501 as a candidate therapeutic for alcohol use disorders. Neuropsychopharmacology 43:1805-1812

Endoh T, Matsuura H, Tanaka C, and Nagase H (1992) Nor-binaltorphimine: a potent and selective kappa-opioid receptor antagonist with long-lasting activity in vivo. Arch Int Pharmacodyn Ther 316:30-42.

Fantegrossi WE, Kugle KM, Valdes LJ III, Koreeda M, and Woods JH (2005) Kappaopioid receptor-mediated effects of the plant-derived hallucinogen, salvinorin A, on inverted screen performance in the mouse. Behav Pharmacol 16:627-633.

Grimwood S, Lu Y, Schmidt AW, Vanase-Frawley MA, Sawant-Basak A, Miller E, McLean S, Freeman J, Wong S, McLaughlin JP, et al. (2011) Pharmacological characterization of 2-methyl- $N$-((2'-(pyrrolidin-1-ylsulfonyl)biphenyl-4-yl)methyl) propan-1-amine (PF-04455242), a high-affinity antagonist selective for $\kappa$-opioid receptors. J Pharmacol Exp Ther 339:555-566.

Hooker JM, Xu Y, Schiffer W, Shea C, Carter P, and Fowler JS (2008) Pharmacokinetics of the potent hallucinogen, salvinorin A in primates parallels the rapid onset and short duration of effects in humans. Neuroimage 41:1044-1050.

Huang P, Tunis J, Parry C, Tallarida R, and Liu-Chen LY (2016a) Synergistic antidepressant-like effects between a kappa opioid antagonist (LY2444296) and a delta opioid agonist (ADL5859) in the mouse forced swim test. Eur J Pharmacol 781:53-59.

Huang P, Yakovleva T, Aldrich JV, Tunis J, Parry C, and Liu-Chen LY (2016b) Two short-acting kappa opioid receptor antagonists (zyklophin and LY2444296) exhibited different behavioral effects from the long-acting antagonist norbinaltorphimine in mouse anxiety tests. Neurosci Lett 615:15-20.

Kalueff AV, Stewart AM, Song C, Berridge KC, Graybiel AM, and Fentress JC (2016) Neurobiology of rodent self-grooming and its value for translational neuroscience. Nat Rev Neurosci 17:45-59.

Khemissi W, Farooq RK, Le Guisquet AM, Sakly M, and Belzung C (2014) Dysregulation of the hypothalamus-pituitary-adrenal axis predicts some aspects of the behavioral response to chronic fluoxetine: association with hippocampal cell proliferation. Front Behav Neurosci 8:340.

Kim SJ, Zheng MQ, Nabulsi N, Labaree D, Ropchan J, Najafzadeh S, Carson RE, Huang Y, and Morris ED (2013) Determination of the in vivo selectivity of a new $\kappa$-opioid receptor antagonist PET tracer ${ }^{11} \mathrm{C}-\mathrm{LY} 2795050$ in the rhesus monkey. J Nucl Med 54:1668-1674.

Ko MC, Willmont KJ, Lee H, Flory GS, and Woods JH (2003) Ultra-long antagonism of kappa opioid agonist-induced diuresis by intracisternal nor-binaltorphimine in monkeys. Brain Res 982:38-44.

Leitl MD, Onvani S, Bowers MS, Cheng K, Rice KC, Carlezon WA Jr, Banks ML, and Negus SS (2014) Pain-related depression of the mesolimbic dopamine system in rats: expression, blockade by analgesics, and role of endogenous $\kappa$-opioids. Neuropsychopharmacology 39:614-624

Lowe SL, Wong CJ, Witcher J, Gonzales CR, Dickinson GL, Bell RL, Rorick-Kehn L, Weller M, Stoltz RR, Royalty J, et al. (2014) Safety, tolerability, and pharmacokinetic evaluation of single- and multiple-ascending doses of a novel kappa opioid receptor antagonist LY2456302 and drug interaction with ethanol in healthy subjects. J Clin Pharmacol 54:968-978.

McLaughlin JP, Land BB, Li S, Pintar JE, and Chavkin C (2006) Prior activation of kappa opioid receptors by U50,488 mimics repeated forced swim stress to potentiate cocaine place preference conditioning. Neuropsychopharmacology 31:787-794.

Melief EJ, Miyatake M, Carroll FI, Béguin C, Carlezon WA Jr, Cohen BM, Grimwood S, Mitch CH, Rorick-Kehn L, and Chavkin C (2011) Duration of action of a broad range of selective $\kappa$-opioid receptor antagonists is positively correlated with c-Jun N-terminal kinase-1 activation. Mol Pharmacol 80:920-929. 
Munro TA and Rizzacasa MA (2003) Salvinorins D-F, new neoclerodane diterpenoids from Salvia divinorum, and an improved method for the isolation of salvinorin A $J$ Nat Prod 66:703-705.

Naganawa M, Dickinson GL, Zheng MQ, Henry S, Vandenhende F, Witcher J, Bell R, Nabulsi N, Lin SF, Ropchan J, et al. (2016) Receptor occupancy of the $\kappa$-opioid antagonist LY2456302 measured with positron emission tomography and the novel radiotracer ${ }^{11} \mathrm{C}-\mathrm{LY} 2795050$. J Pharmacol Exp Ther 356: 260-266.

Naganawa M, Zheng MQ, Henry S, Nabulsi N, Lin SF, Ropchan J, Labaree D, Najafzadeh S, Kapinos M, Tauscher J, et al. (2015) Test-retest reproducibility of binding parameters in humans with 11C-LY2795050, an antagonist PET radiotracer for the $\kappa$ opioid receptor. J Nucl Med 56:243-248.

Naganawa M, Zheng MQ, Nabulsi N, Tomasi G, Henry S, Lin SF, Ropchan J, Labaree D, Tauscher J, Neumeister A, et al. (2014) Kinetic modeling of ${ }^{11}$ C-LY2795050, a novel antagonist radiotracer for PET imaging of the kappa opioid receptor in humans. J Cereb Blood Flow Metab 34:1818-1825.

Paris JJ, Reilley KJ, and McLaughlin JP (2011) Kappa opioid receptor-mediated disruption of novel object recognition: relevance for psychostimulant treatment. $J$ Addict Res Ther S4:007.

Peckham EM and Traynor JR (2006) Comparison of the antinociceptive response to morphine and morphine-like compounds in male and female Sprague-Dawley rats. $J$ Pharmacol Exp Ther 316:1195-1201.

Peters MF, Zacco A, Gordon J, Maciag CM, Litwin LC, Thompson C, Schroeder P, Sygowski LA, Piser TM, and Brugel TA (2011) Identification of short-acting $\kappa$-opioid receptor antagonists with anxiolytic-like activity. Eur $J$ Pharmacol 661: $27-34$.

Pietrzak RH, Naganawa M, Huang Y, Corsi-Travali S, Zheng MQ, Stein MB, Henry S, Lim K, Ropchan J, Lin SF, et al. (2014) Association of in vivo $\kappa$-opioid receptor availability and the transdiagnostic dimensional expression of trauma-related psychopathology. JAMA Psychiatry 71:1262-1270.

Placzek MS, Schroeder FA, Che T, Wey HY, Neelamegam R, Wang C, Roth BL, and Hooker JM (2019) Discrepancies in kappa opioid agonist binding revealed through PET imaging. ACS Chem Neurosci 10:384-395.

Porsolt RD, Bertin A, and Jalfre M (1978) "Behavioural despair" in rats and mice: strain differences and the effects of imipramine. Eur $J$ Pharmacol 51: 291-294.

Portoghese PS, Lipkowski AW, and Takemori AE (1987) Binaltorphimine and norbinaltorphimine, potent and selective kappa-opioid receptor antagonists. Life Sci 40:1287-1292.

Reed B, Butelman ER, Fry RS, Kimani R, and Kreek MJ (2018) Repeated administration of opra kappa (LY2456302), a novel, short-acting, selective KOP-r antagonist, in persons with and without cocaine dependence. Neuropsychopharmacology 43:739-750.

Reed B, Fang N, Mayer-Blackwell B, Chen S, Yuferov V, Zhou Y, and Kreek MJ (2012) Chromatin alterations in response to forced swimming underlie increased prodynorphin transcription. Neuroscience 220:109-118.

Rorick-Kehn LM, Witkin JM, Statnick MA, Eberle EL, McKinzie JH, Kahl SD, Forster BM, Wong CJ, Li X, Crile RS, et al. (2014) LY2456302 is a novel, potent, orally-bioavailable small molecule kappa-selective antagonist with activity in animal models predictive of efficacy in mood and addictive disorders. Neuropharmacology 77:131-144.
Rorick-Kehn LM, Witcher JW, Lowe SL, Gonzales CR, Weller MA, Bell RL, Hart JC, Need AB, McKinzie JH, Statnick MA, et al. (2015) Determining pharmacological selectivity of the kappa opioid receptor antagonist LY2456302 using pupillometry as a translational biomarker in rat and human. Int $J$ Neuropsychopharmacol 18 pyu036.

Roth BL, Baner K, Westkaemper R, Siebert D, Rice KC, Steinberg S, Ernsberger P, and Rothman RB (2002) Salvinorin A: a potent naturally occurring nonnitrogenous kappa opioid selective agonist. Proc Natl Acad Sci USA 99:11934-11939.

Sens J, Schneider E, Mauch J, Schaffstein A, Mohamed S, Fasoli K, Saurine J, Britzolaki A, Thelen C, and Pitychoutis PM (2017) Lipopolysaccharide administration induces sex-dependent behavioural and serotonergic neurochemical signatures in mice. Pharmacol Biochem Behav 153:168-181.

Shirayama Y, Ishida H, Iwata M, Hazama GI, Kawahara R, and Duman RS (2004) Stress increases dynorphin immunoreactivity in limbic brain regions and dynorphin antagonism produces antidepressant-like effects. J Neurochem 90:1258-1268.

Tidgewell K, Harding WW, Schmidt M, Holden KG, Murry DJ, and Prisinzano TE (2004) A facile method for the preparation of deuterium labeled salvinorin A: synthesis of [2,2,2-2H3]-salvinorin A. Bioorg Med Chem Lett 14:5099-5102.

Unterwald EM, Rubenfeld JM, and Kreek MJ (1994) Repeated cocaine administration upregulates kappa and mu, but not delta, opioid receptors. Neuroreport 5: $1613-1616$

Valenza M, Butelman ER, and Kreek MJ (2017) Effects of the novel relatively shortacting kappa opioid receptor antagonist LY2444296 in behaviors observed after chronic extended-access cocaine self-administration in rats. Psychopharmacology (Berl) 234:2219-2231.

Van't Veer A and Carlezon WA Jr (2013) Role of kappa-opioid receptors in stress and anxiety-related behavior. Psychopharmacology (Berl) 229:435-452.

Williams AV, Laman-Maharg A, Armstrong CV, Ramos-Maciel S, Minie VA, and Trainor BC (2018) Acute inhibition of kappa opioid receptors before stress blocks depression-like behaviors in California mice. Prog Neuropsychopharmacol Biol Psychiatry 86:166-174.

Yalcin I, Belzung C, and Surget A (2008) Mouse strain differences in the unpredictable chronic mild stress: a four-antidepressant survey. Behav Brain Res 193: 140-143.

Zhang Y, Butelman ER, Schlussman SD, Ho A, and Kreek MJ (2004) Effect of the endogenous kappa opioid agonist dynorphin A(1-17) on cocaine-evoked increases in striatal dopamine levels and cocaine-induced place preference in C57BL/6J mice. Psychopharmacology (Berl) 172:422-429.

Zhang Y, Butelman ER, Schlussman SD, Ho A, and Kreek MJ (2005) Effects of the plant-derived hallucinogen salvinorin A on basal dopamine levels in the caudate putamen and in a conditioned place aversion assay in mice: agonist actions at kappa opioid receptors. Psychopharmacology (Berl) 179:551-558.

Zheng MQ, Nabulsi N, Kim SJ, Tomasi G, Lin SF, Mitch C, Quimby S, Barth V, Rash K, Masters J, et al. (2013) Synthesis and evaluation of 11C-LY2795050 as a kappaopioid receptor antagonist radiotracer for PET imaging. J Nucl Med 54:455-463.

Address correspondence to: Dr. Eduardo R. Butelman, The Rockefeller University (Box 171), 1230 York Ave, New York, NY 10065. E-mail: butelme@ rockefeller.edu 